Tracing new ground, from language to languaging, and from languaging to assemblages: Rethinking languaging through the multilingual and ontological turns

Gurney, L. and Demuro, E.

Correspondence details

Dr Laura Gurney

Te Kura Toi Tangata School of Education, University of Waikato

Private Bag 3105, Hamilton 3240, New Zealand

Phone: +64 78389563

Email: laura.gurney@waikato.ac.nz

Notes on contributors

Dr Laura Gurney is Lecturer in Te Kura Toi Tangata School of Education, University of Waikato, Hamilton, New Zealand. She specialises in languages education.

Dr Eugenia Demuro is Senior Lecturer in Spanish and Latin American Studies at Deakin University; and the Course Director of the Bachelor of International Studies. Dr Demuro has a background in sociology and literary theory. 


\title{
Tracing new ground, from language to languaging, and from languaging to assemblages: Rethinking languaging through the multilingual and ontological turns
}

\begin{abstract}
This paper traces recent theorisation stemming from the multilingual turn and brings this into dialogue with assemblage thinking, discussing the critical potential of bringing these perspectives together to explore what language is and how it is understood. The argument maps salient features of the multilingual turn which have extended the fields of applied and socio-linguistics beyond a preoccupation with separable languages embedded within a code-based depiction of linguistic behaviour. Within this body of research, we highlight the influential theoretical frames of (trans)languaging and metrolingualism, which position language as a dynamic process — and practice-rather than a product. We then begin to think through language/languaging as assemblage, a process which heralds an ontological shift. In so doing, we consider the ontological turn within and beyond linguistics to extend the potential of critical language studies, breaking with hegemonic language ideology via a radical reconsideration of the temporality, complexity and materiality of language.
\end{abstract}

Keywords: multilingualism; languaging; translanguaging; metrolingualism, assemblages; ontology; Deleuze and Guattari

\section{Introduction}

Studies on language ideology (Makoni \& Pennycook, 2006; Woolard \& Schieffelin, 1994) have demonstrated that hegemonic accounts of language are neither neutral nor given but rather a) socially constructed; b) invented and political - in so far as they construct a particular world (hetero-patriarchal, colonial/imperial, classist); and c) inseparable from culture (Demuro \& Gurney, 2018; Gramling, 2016). Makoni and Pennycook (2006) define languages as a social invention inseparable from other social constructions and semiotic processes, heavily influenced by racial and nationalist ideologies, mediated through metadiscursive regimes such as grammars and dictionaries, and carrying material 
consequences.

Hegemonic accounts of language, embedded within sociohistorical processes and predicated on language separability and monolingualism as default, have limited exploration of what language might be. These accounts, corresponding to the 'language myth’ (Harris, 1980; Love, 2004), configure language as a bounded object and product. Although such perspectives have been critically examined and challenged from a number of standpoints (Kubota \& Miller, 2017; Orman, 2013), they continue to wield legitimacy in academic studies of language, language policy and planning, languages education, and everyday accounts of 'correct' language use. One of the definitive elements of dominant accounts has been the promotion of the language practices of a community as an essential aspect of its cultural—and, by extension, political—identity (Del Valle, 2000); given the prominence of the nation state as the principal unit of community, so the key unit by which many languages have been measured has correlated to the boundaries of the nation state. While there have been concerted critiques of the pairing of language and nation (Canagarajah, 2006; Li, 2018; Makoni \& Pennycook, 2006; Mar-Molinero, 2004, among others), this remains a persistent feature of linguistic essentialism.

Moving away from conceptions that unproblematically link language to culture, ethnicity and nation, we begin by broadly tracing theorisation within and beyond the recent multilingual, or post-monolingual, turn. This turn has included, but is not limited to, work on multi- and pluri-lingualism (Canagarajah \& Ashraf, 2013; Marshall \& Moore, 2018), metrolingualism (Otsuji \& Pennycook, 2010; Pennycook \& Otsuji, 2014, 2019), and languaging and translanguaging (García \& Li, 2014; Li, 2018), which operationalise conceptions of language more readily linked to embodied interpretation, negotiation and (re)production in inter- and intra-action. As will be argued, these elements of the multilingual 
turn mark a paradigmatic shift from language as object towards a conception of language (or languaging) as practice. ${ }^{\mathrm{i}}$

As this area of theorisation evolves, the assemblage has begun to gain traction. An incipient discussion of language as assemblage, or the semiotic assemblage, is noted in recent scholarship (see Appleby \& Pennycook, 2017; Pennycook, 2017, 2018a, 2018b; Pennycook \& Otsuji, 2019). However, critical engagement with what assemblage thinking might mean in the context of language studies is still in its infancy. To contribute to this discussion, this paper draws on an interdisciplinary body of work to bring the assemblage into dialogue with poststructuralist elements of the multilingual turn, particularly work in (trans)languaging and metrolingualism. The aims of the paper are to position assemblage thinking in relation to recent approaches in language studies, develop understandings of the language assemblage, and point tentatively to some outcomes for analysis.

Assemblage thinking is intrinsically interdisciplinary, prompting us to think beyond (and about) boundaries, and to consider how we demarcate 'language' - as a product, practice, or other. Assemblages are defined by the non-hierarchical coming together and breaking apart of their constituent components; key to bringing together seemingly discordant perspectives (for example, the ideology of monolingualism and the practice of translanguaging), the assemblage involves both the ideological/discursive frames and the material components of language. Arguably, assemblage thinking prompts the reconfiguration of the constituent parts of language/languaging and has the capacity to capture elements of different ontological status, including ideological and material. The language assemblage has unique characteristics which set it apart from other assemblages, and yet remains in constant interplay with assemblages "that are not principally linguistic" (Deleuze \& Guattari, 1987, p. 111). 
By building on existing critical scholarship developing in language studies, we respond to Thurlow’s (2016) mandate not to “deny language but to provincialize it: to recognize its limits, to acknowledge its constructedness, and to open ourselves up to a world of communicating and knowing beyond - or beside/s - words” (p. 503). This paper is a tentative step towards the possibilities of re-thinking language/languaging in this direction and aims to contribute to a discussion that opens up further questions and reflections on the linguistic assemblage.

\section{Models of multilingualism: From multiple monolinguals to (trans)languaging}

The multilingual turn (May, 2014) has initiated “a paradigm shift in applied linguistics” (Canagarajah, 2017, p. 1). This turn has broadly challenged core assumptions concerning language; yet, prominent elements of the multilingual turn continue to refract language through a structuralist lens, based on a separationist ontology, where focus has shifted from the use of single codes to the mixing of (still) discrete codes. As Otsuji and Pennycook (2010) state, “one of the underlying ideologies of multilingualism and multiculturalism is that people and associated practices are composed of multiple discrete languages and cultural practices” (p. 243). Despite support for more holistic and integrationist positions (Orman, 2013), including recent work in translanguaging ( $\mathrm{Li}, 2018)$, theoretical representations of multilingualism and, by extension, language practice in general, remain discordant and in part reproductive of inherited, orthodoxical ideologies which promote multiplication of languages but prejudice efforts to complexify language beyond determined categories.

\section{Linguistic orthodoxy and multilingualism: Multiplying the monolingual}

The construct of language codes which categorises language users as mono-, bi-, tri- or multilingual informs ensuing discussions of multilingualism and the latent depictions of linguistic behaviour that they transmit. Monolingualism, according to Gramling (2016), was an 
innovation of the early modern and Enlightenment period in Europe - a scientific-aesthetic invention that "first made the Mercatorian notion of countable global cultures and languages at least provisionally thinkable” (p. 2). In his discussion of the invention of monolingualism within a European context, Gramling (2016) describes pre-monolingual norms of communication in early modern Europe as language practices unconcerned with replicability or standardisation. In other words, language practices within and between communities were not subordinated to the rules of identified languages. ${ }^{\text {ii }}$ Subsequently, a broad project was undertaken to invent and standardise discrete languages in a "pluralizable, panfunctional grid of rational extension” (Gramling, 2016, p. 2), linked strongly to colonialism and nationbuilding. This process is explored in depth by Demuro and Gurney (2018) in the context of the creation and operalisation of Castilian Spanish within Europe and the Americas. The ideological force engendering this project came to dominate the fields of linguistics and language education, obscuring pre-modern practices and replacing these with a totalising linguistic orthodoxy premised on structuralism and governed by purism. This is also referred to as the culture and practice of monoglossia, which many poststructuralist critiques address. Monoglossia draws on two principles: the first is focused grammar, "that what linguistically characterizes an individual as well as a community is possession of a well defined and relatively stable grammar” (Del Valle, 2000, p. 119); the second is convergence, "the assumption that people’s linguistic behavior tends to become homogeneous over time through pressure from the dominant norm of the community” (Del Valle, 2000, p. 120).

The epistemological inheritance of monolingualism and monoglossia is traceable in the positivistic approaches which came to govern twentieth century linguistics (Harris, 1999; Love, 2004, 2009; Makoni \& Pennycook, 2006; McNamara, 2012) and which paved the way for associated notions such as standard language, language purity, (non-)native language users, proficiency levels and processes of language acquisition, as well as the connections 
between language, culture, ethnicity, nation/territory and nationality (Kubota \& Miller, 2017; Orman, 2013). Despite Love’s (2009) contention that “much of what has passed for a science of language over the last 150 years has been nothing but an exercise in culture maintenance” (p. 31), these concepts continue to wield significant power in education and other spheres but have generally remained uncontested, or hidden, in practice. This linguistic orthodoxy is promoted, for example, through language policy and planning efforts designating languages of instruction, official languages within national borders, and language use in prestigious domains such as government and law; in much educational practice; in metadiscursive regimes asserting definitive authority on correctness; in the practices underpinning translation and interpreting; and in attitudes towards language use in publishing. More recent, neoliberal conceptions of language as an abstract tool for communication and information transfer, to be acquired by entrepreneurial individuals (Park, 2016), are also premised on and reproductive of these assumptions. ${ }^{\text {iii }}$

Conceptualisations of multilingualism premised on monolingualism are persistent. In critiquing the continued reliance on separable language codes within the multilingual turn, Orman (2013) states

[m]uch contemporary sociolinguistic theorising exhibits a curious characteristic [...] while it is readily willing to embrace what might be termed a post- or late-modern sociological perspective whereby notions such as fluidity, flux, hybridity (e.g. Otsuji and Pennycook, 2010) and so on are to the fore and there is a pervasive scepticism towards essentialist and determinate social categorisations, when it comes to linguistic analysis it all too often seeks out the comforting certainty of a traditional structuralist approach whereby the expert researcher implicitly claims to be able to read off both social and linguistic meanings from the features attested in the 'data', hence the continued reference to codes, systems, etc. The underlying ontology of language and communication remains all but unchanged. (emphasis added, p. 97)

An illustrative example is code-mixing, or code-switching. Code-mixing/switching is defined 
as the "fluent integration of two languages within a single utterance" (Goldrick, Putnam, \& Schwarz, 2016, p. 857), or changing between language codes during production (see also Auer, 2011). The ability to change between codes is necessarily premised on the recognition of separate codes as valid categories (or, separability as a valid property of language); without this recognition, mixing or switching would be unthinkable propositions. As Li (2018) contests, “code-mixing and code-switching ... assume the existence of different languages as structural and cognitive entities and focus on structural configurations of the form” (p. 13), and fail to provide a satisfactory account of linguistic behaviour outside these boundaries. This approach also reinforces the notion of language purity and the assumption that languages operate externally to language users (Demuro \& Gurney, 2018), characterised by a relatively “stable linguistic architecture” (Thibault, 2017, p. 75).

In line with critiques presented by Orman (2013) and others, such assumptions have been contested from a number of theoretical bases. From a languages education perspective, there have been calls to sidestep the commodity view of language implied by structuralist depictions, as "something that moves from the external to the internal, something that gets taken in” (Larsen-Freeman, 2015, p. 493), in lieu of a more complex understanding of language as evolving and emerging through use and negotiation, rather than simply absorption or access, by learners. Similarly, recent research exploring language from a cognitive perspective contests separation of codes, suggesting that individuals are able to activate elements of apparently discrete languages flexibly and spontaneously during production (Goldrick et al., 2016). However, while such research problematises depictions of language use based on separation, including those which proposed language lateralisation as a basis for the separation of language in bi- and multilinguals, it does little to contest the validity of language separability on a conceptual level. In short, key accounts of multilingualism continue to be informed by, and to assume, language as object and language 
users as “input-output systems that use language to 'represent' and 'communicate' information by means of mental representations housed in the brain of each individual” (Thibault, 2011, p. 211).

Structuralism has also been contested for some time by integrational linguists (including Harris, 1999; Love, 2004, 2006; Toolan, 2003), who have labelled the assumption that “a language is an inventory of determinately identifiable linguistic units, each of which correlates a form with a meaning or meanings ... a fixed code” (Love, 2004, p. 529) as the language myth. Integrationism "resists and rejects attempts to reduce human linguistic and communicative endeavours to an analysis based on the postulation of rules, objects and systems” (Orman, 2013, p. 91). Rather, integrationists understand communication as a creative activity where participants make and remake the signs they use to communicate meaning-as language makers rather than language users (Harris, 1980). Furthermore, integrationists do not separate domains of meaning-making, whether verbal, gestural or other (Orman, 2013). Subsequently, (re)invention and (re)negotiation are considered constitutive of non-mythic accounts of linguistic behaviour. Languages are inventions (Orman, 2013) which may constrain and shape potential language dynamics, but do not precede communicative behaviour (Thibault, 2011). The integrationist rejection of a segregational and structuralist view of language, which began some time ago, set the scene for further practice-based approaches to language. More recently taken up by theorists operating within poststructuralist branches of the multilingual turn, these approaches include (trans)languaging and metrolingualism.

\section{From abstract language to grounded languaging: Translanguaging and metrolingualism}

(Trans)languaging responds to the push to complexify the frameworks through which linguistic practice is seen and understood (see Becker, 1991; García \& Li, 2014; Lewis, 
Jones, \& Baker, 2012; Li, 2018; Pennycook, 2017). In opposition to the term 'language', as static and fixed, languaging is defined as action, and has been linked to a praxis "in and through which language events are achieved and recognized in culturally saturated interactivity between persons” (Thibault, 2017, p. 76).

(Trans)languaging propels us to re-think how users interact with language, “not as an organism centred entity with corresponding formalism, phonemes, words, sentences, etc., but as a multi-scalar organization of processes that enables the bodily and the situated to interact with situation-transcending cultural-historical dynamics and practices” (Li, 2018, p. 17, emphasis added). This term shifts language from a noun to a verb (Bloome \& Beauchemin, 2016), originating not in abstract systems with an arbitrary relationship to sounds and signs, but grounded within idiolectical, cultural and experiential approaches to communication and interaction (see Becker, 1991).

Li (2018) and others (see García \& Li, 2014; Lewis et al., 2012) add the prefix transto languaging to contextualise the term within multilingual language use, positing that translanguaging captures multilinguals’ creative, fluid, and hybrid language practices. The term 'translanguaging' has its origins in studies of bilingual education and pedagogy: “[p]articularly in the bilingual classroom, translanguaging as a concept tries to move acceptable practice away from language separation, and thus has ideological - even political - associations” (Lewis et al., 2012, p. 659). Li (2018) moreover emphasises the importance of the trans prefix for capturing the transcendence of "socially constructed language systems" (p. 27), the transformative capacity of the translanguaging process, and the transdisciplinary consequences of reconceptualising language in this way. ${ }^{\text {iv }}$ Translanguaging does not merely address the use of, or shift between, two or more languages, but aims to theorise processes at play that cannot be readily identified through structuralist accounts by capturing the “construction and use of original and complex interrelated discursive practices [...] that make 
up the speakers’ complete language repertoire” (García \& Li, 2014, p. 22). Translanguaging thus comes to be understood as a practice permeating the borders of discrete languages and leading to "a linguistics of participation” (Li, 2018, p. 15). Translanguaging is readily distanced from the ideology of monolingualism, and encompasses instead "a variety of cognitive, semiotic, and modal resources of which language in its conventional sense of speech and writing is only one” (Li, 2018, p. 18). In this respect, it is notable that translanguaging as a theory aims to provide a more complex-or exhaustive-account of language processes, looking to the practices of so-called multilinguals (while also eroding the need for the term multilingual) to understand how linguistic behaviours are shaped by morethan-linguistic elements, beyond discrete language codes.

Another emergent approach which problematises a monoglossic conception of language is metrolingualism. Otsuji and Pennycook (2010; see also Pennycook \& Otsuji, 2014; Pennycook \& Otsuji, 2019), theorising principally within “urban environments” (p. 241) and other contexts of migration and movement, propose to extend Maher's (2005) notion of metroethnicity to metrolingualism, referring to "creative linguistic conditions across space and borders of culture, history and politics, as a way to move beyond current terms such as multilingualism and multiculturalism” (p. 244, emphasis in original).

Metrolingualism aims to overcome statist connections between language and nation/territory, and the associated corollaries of ethnicity, culture and geography. Like (trans)languaging, metrolingualism shifts its focus away from the reproduction of language systems to language as a product of interaction. However, in this case, emphasis is placed on the assumed relations between language and its corollaries, and how these relations may be inverted or changed. As Otsuji and Pennycook (2010) explain

[m]etrolingualism describes the ways in which people of different and mixed backgrounds use, play with and negotiate identities through language; it does not assume 
connections between language, culture, ethnicity, nationality or geography, but rather seeks to explore how such relations are produced, resisted, defied or rearranged; its focus is not on language systems but on languages as emergent from contexts of interaction. (p. 246)

Metrolingualism draws on linguistic playfulness as key to an emancipatory political agenda, ${ }^{\mathrm{v}}$ involving the deliberate undoing of structuralist, statist and nationalist ideologies, and producing new possibilities for languaging. It is, and this is a defining characteristic, “a way of describing diverse grounded local practices” (Otsuji \& Pennycook, 2010, p. 248). The authors further contend that language production is in a constant state of fixity and fluidity, caught between ideological impetuses to adhere to ortholinguistic notions of purity, correctness and the separation of language codes while negotiating new spaces and possibilities for linguistic behaviour on the ground (Pennycook \& Otsuji, 2014). A significant feature of this is the production of identities that are materially grounded.

Seen through the discussion of (trans)languaging and metrolingualism, the turn away from monolingualism and towards the theorisation of language plurality can be best understood as a rejection of "the ontologically real status of discrete, enumerable languages" (Orman, 2013, p. 92). The shift to language as practice, the explicit acknowledgment of nonlinguistic elements in language negotiation and (re)production, and the consideration of diverse grounded practices all challenge normative accounts of language as defined through dominant ideologies. Here, language, or languaging, is a set of situated and territorialised social practices belonging to users and interactants (Otsuji \& Pennycook, 2010). These practices are embodied and distributed, taking place within and woven into a spatial repertoire and wider set of interactions (Li, 2018; Pennycook, 2017). However, such assertions have led to new spaces of inquiry; for example, questions of who or what the actants in what we consider language might be - whether language inheres in and across species, and (in)organic and (non)sentient entities - are quickly generated. As we move away 
from codes located within bounded territories, we consider how we might better account for a plethora of apparently heterogeneous elements imbricated into a reconfigured notion of languaging.

\section{From languaging to assemblages}

While the assemblage has recently attracted attention in language studies, there remains much space for discussion concerning how assemblage thinking can contribute to our understandings of language/languaging. ${ }^{\mathrm{vi}}$ To this end, this paper further imagines the implications and scope of assemblage thinking in language studies via engagement with both the Deleuzian origins of the assemblage and the significant application of assemblage thinking across domains of research. In this section, we outline the implications, and consider the benefits, of assemblage thinking vis-à-vis language. Our discussion does not aim to counter or dismantle salient poststructuralist accounts of language/languaging, but rather to engage more explicitly with, as Li (2018) signals, the "transdisciplinary consequences of reconceptualizing language, language learning, and language use, and working across the divides between linguistics, psychology, sociology, and education [and beyond]” (p. 27). While the concept of the assemblage was not (necessarily) developed as an analytical tool per se, in this context, assemblage thinking is a propitious perspective. Furthermore, it has been applied in a variety of research areas (see for example Acuto \& Curtis, 2014; Brenner, Madden, \& Wachsmuth, 2011; Fox \& Alldred, 2015; Greenhough, 2012; Wood, 2013).

The assemblage provides a unique philosophical framework to think through the constitutive relations of complex, overlapping and heterogeneous processes into recognised, though temporary or unfixed, groupings which themselves are able to produce new possibilities for thought, action and organisation. Following Deleuze and Guattari's $A$ thousand plateaus (1987), the notion of assemblages (subsequently referred to by DeLanda as 
assemblage theory) has been harnessed to extend understandings of human and more-thanhuman interactivity, agency and causality, encompassing the ways in which activities, processes and occurrences are ascribed to actants, and inscribed within interactions, occurring across time and space. Assemblages synthesise "conditions, consequences, and activity of desire as a process of production” (Litaker, 2014, p. 252).

To begin, assemblage thinking has potential to (re)configure language/languaging along the following axes:

- $\quad$ as situated across time and space; that is, both in relation to grounded material conditions and as taking place within, and at, particular times (moments);

- as situated at the interface of material and non-material/ideal planes. In this sense, language/languaging can be conceived as (intra)action (Barad, 2007) and practice (deliberate or otherwise), shaped by but also occurring beyond the salient ideological frames which are imposed onto it; and

- $\quad$ as able to be re- and de-territorialised; in other words, language/languaging reifies and/or diverges from what has come before (parole, or languaging practice), but is always the production of something new.

Assemblages problematise the modernist ideological separation (or bifurcation) of the ideal and the material into different ontological categories, bringing together elements which may otherwise be separated into social, cultural, political, linguistic, biological, natural, technological, or virtual domains. As inherently plural, assemblages establish connectivity between multiplicities (Deleuze \& Guattari, 1987), ${ }^{\text {vii }}$ in other words: they are groupings which comprise heterogeneous components linked and acting together. It is in the interaction of these elements (or, what Barad has denominated the intra-action) - the meeting and generation of strands of relation between them - that the assemblage is recognisable. As a 
philosophical concept, assemblages provide an entry point to understand the complexity inherent within phenomena and practices which have otherwise been treated as singular and irreducible.

An assemblage is not an organic unity from which discrete parts are derived; rather, the relations which join the heterogeneous parts of an assemblage are those of exteriority. Unities are wholes made up of component parts, the properties of which are dependent on their relations with one another. ${ }^{\text {viii }}$ Assemblages are multiplicities which can shift apart and recombine without changing the properties of their constitutive components. Furthermore, these properties alone cannot explain the relations which constitute the assemblage (DeLanda, 2006). Assemblages “establish territories as they emerge and hold together but also constantly mutate, transform and break up” (Müller, 2015, pp. 28-29). ${ }^{\text {ix }}$

The assemblage is characteristically defined by a state of being-in-flux. As productive and relational groupings, assemblages have no essence; they do not recognise the possibility of a final product or unit with necessary features but comprise "contingent features at a certain point in [an] incomplete process” (Nail, 2017, p. 24). As DeLanda (2006) explains, drawing on Deleuze and Guattari, the identity of an assemblage is "the product of a process (territorialisation and, in some cases, coding) and it is always precarious, since other processes (reterritorialization and decoding) can destabilize it” (p. 28). That is, assemblages may be altered or dismantled in a process of deterritorialisation, or they may be reinforced through reterritorialisation. However, assemblages are not simply randomly generated and degenerating frameworks: there is an underlying arrangement to assemblages which allow them to be recognised as such:

[w]e may draw some general conclusions on the nature of Assemblages [...]. On a first, horizontal, axis, an assemblage comprises two segments, one of content, the other of expression. On the other hand it is a machinic assemblage of bodies, of actions and 
passions, an intermingling of bodies reacting to one another; on the other hand it is a collective assemblage of enunciation, of acts and statements, of incorporeal transformations attributed to bodies. Then on a vertical axis, the assemblage has both territorial sides, or reterritorialized sides, which stabilize it, and cutting edges of deterritorialization, which carry it away. (Deleuze \& Guattari, 1987, p. 88) ${ }^{\mathrm{X}}$

Significantly, assemblages are not governed by a central body, head or actant. As assemblages are horizontal, they have no predetermined hierarchies or single organising principles: entities within assemblages have an equivalent ontological status (Müller, 2015 p. 28). ${ }^{\mathrm{xi}}$ Furthermore, assemblages are more than simply combinations of their constituent parts or a way to name groups; they are capable of producing new organisations, behaviours, actors and realities (Fox \& Alldred, 2015; Müller, 2015). Phillips (2006) underscores the assemblage as privileging precisely the connections between its constituent parts.

'Agencement', Phillips (2006) writes, "implies the production of a sense that exceeds them and of which, transformed, they now form parts” (p. 108).

The assemblage's complex, non-hierarchical, and flexible framework lends itself to underscore a conception of language/languaging which accommodates the inevitability of transformation (see Wood, 2013), and the “yoking together” of different kinds of entities to produce situations, events and possibilities (Buchanan, 2017). If one is to posit the assemblage as a mode of approaching language, then it becomes possible to apprehend language as that which is produced through the interactions between heterogeneous actants in combination and relation to each other, and determined within particular, yet ever changing, contexts. The assemblage also allows us to recognise the intersection of language assemblages with other assemblages ('language', as a way to name and classify languaging and other assemblages, is an important component of their recognition under contemporary conditions). 
Assemblage thinking is not only a way to (re)conceptualise language but has potential to strengthen critical responses to limiting (and, in many cases, damaging) language ideologies. Assemblage thinking also allows us to take seriously persistent ideologies of language, such as monolingualism/monoglossia, and to comprehend their longevity (if, as much critical research has contended, they are not satisfactorily representative of dynamic languaging practice); the codes; the ideologies, the socio-political and economic conditions that originated and sustain these, and the artefacts that transmit them (connected to all of the previous), are themselves actants in the assemblage which produce and delimit possibilities for language users - i.e. they cause the assemblage to reterritorialise. At every moment, they intra-act with and shape the material conditions which are the substrate of languaging.

Indeed, Deleuze and Guattari (1987) criticised dominant linguistic models extensively, stating that the preoccupation with constants (syntactical, morphological, and/or phonological) "botches the assemblage; it consigns circumstances to the exterior, closes language in on itself, and makes pragmatics a residue” (p. 82). They categorised dominant linguistic models as "not abstract enough", in that they "do not reach the abstract machine that connects a language to the semantic and pragmatic contents of statements, to collective assemblages of enunciation, to a whole micropolitics of the social field” (p. 7). To provide further illustration, they describe semiotic chains thus:

[a] semiotic chain is like a tuber agglomerating very diverse acts, not only linguistic, but also perceptive, mimetic, gestural, and cognitive: there is no language in itself, nor are there any linguistic universals, only a throng of dialects, patois, slangs, and specialized languages. There is no ideal speaker-listener, any more than there is a homogeneous linguistic community ... there is no mother tongue, only a power takeover by a dominant language within a political multiplicity. (Deleuze \& Guattari, 1987, p. 7)

This 'power takeover' names the dominant ideological positions imposed upon the throng of individual and collective language practices to which the authors refer. To avoid closing 
language in on itself, assemblage thinking can contextualise so-called constants of language within a broader set of interacting elements in a non-hierarchical way.

The relationship between conceptions of language and what Deleuze and Guattari call assemblages of enunciation, as well as machinic assemblages (expression and content, respectively), warrants further and ongoing discussion. The roles and ascribed nature of language - as physical, ideal, collective, idiosyncratic, (more-than-) human, fixed or in-flux, purportedly representational as well as analysable - render it a difficult phenomenon to capture through theoretical frames which privilege any one of these characteristics over the others. Language, if it is to be identified as a discrete phenomenon, is made possible by its separation from bodies (Deleuze, 1990); the attribution of "expressive function” (Deleuze, 1990, p. 181) following the separation illustrates the at once materiality and ideality of language, drawing on and situated within social and political multiplicities. ${ }^{\text {xii }}$ Furthermore, the assumed representational quality of language (where language is taken as a legitimate way to construct the world) is recast as it inhabits this horizontalised state (see also MacLure, 2013). In other words, assemblages of enunciation do not speak about things, but rather speak "on the same level as states of things and states of content. So that the same $x$, the same particle, may function either as a body that acts and undergoes actions, or as a sign constituting an act or order-word, depending on which form it is taken up by” (Deleuze \& Guattari, 1987, p. 87).

Temporality, the horizontal plane of languaging, and the complication of expression and content/bodies/events constitute the appeal of the assemblage as a way of probing what has been defined as language and exploring what language can do and what it might be. From the perspective of assemblages, language cannot satisfactorily be defined as object or system, but is conceived in line with the relations between the constituent elements imbricated within (more-than) linguistic events. Simultaneously, it cannot only be viewed as practice enacted, 
determined and controlled by particular language users, due to the ways in which power enters into assemblages.

As a theoretical proposition, assemblage thinking invites us to reconsider the ineluctability of the constituents of languaging. Do the same constituents (sounds, gestures, signs, ideologies of communication) always form part of language assemblages? If not, what are the indispensable constituents of a language assemblage in order to recognise it as such? Pennycook (2017) posits that the semiotic assemblage "relocates repertoires in the dynamic relations among objects, places and linguistic resources, an emergent property deriving from the interactions between people, artefacts and space” (p. 279). However, elements of the language assemblage extend beyond (before, during, after) communicative interactions; the recognition of the assemblage is interpellated by ideologies of communication and frames of interaction. Deleuze and Guattari (1987) explicitly note the intersection of semiotic systems within social systems:

semiotic systems depend on assemblages, and it is the assemblages that determine that a given people, period, or language, and even a given style, fashion, pathology, or minuscule event in a limited situation, can assure the predominance of one semiotic or another. (p. 119) ... we are not saying that a people invents this regime of signs, only that at a given moment a people effectuates the assemblage that assures the relative dominance of that regime under certain historical conditions. (p. 121)

Assemblage thinking captures this complexity, while accommodating language codes and languaging processes, political and social systems, the behaviours and thoughts of individuals, the material 'tools' and contexts of languaging, and so on. By bringing the immaterial (culture, ideology, theoretical frames) into play with the material (sounds, signs, electrical impulses), the assemblage allows us to think comprehensively about what languaging might consist of, without presupposing any components as inherent to or ineluctable within the assemblage. From this perspective, it is not possible to analyse 
semiosis separately from other phenomena: "there is always a form of content that is simultaneously inseparable from and independent of the form of expression, and the two forms pertain to assemblages that are not principally linguistic” (Deleuze \& Guattari, 1987, p. 111, emphasis added).

\section{Considering assemblages and analysis}

Inevitably, theorisation of language or languaging arises from within and, in turn, reconfigures (modulates and reproduces) dynamic assemblages. Knowledge about language and other phenomena is communicated and performed via 'language' in ever forming and (re)forming assemblages. Standardised versions of dominant languages carry socio-political prestige and cultural legitimacy; these perceived forces, and our reactions to them, are also actants within the assemblage. ${ }^{\text {xiii }}$ Through our use of configured language, the possibilities for imagining (or deterritorialisation) are to a certain extent predetermined as we are situated within social fields and formal codes. Furthermore, in discussing the language assemblage, we are always speaking within and across that assemblage (within and across multiple assemblages) which comprises not only propositions and concepts but also matter. The assemblages in which language is caught up comprise elements that are more-than-semiotic in nature. ${ }^{\text {xiv }}$

As an analytical tool, the assemblage presents a way of unravelling, or unpacking, a given situation or set of practices. Following Buchanan’s (2017) discussion,

the critical analytic question is always: given a specific situation, what kind of assemblage would be required to produce it? ... what are the material elements - bodies in the broadest possible sense - that constitute this 'thing', how are they arranged, what relations do they entail, what new arrangements and relations might they facilitate? On the other hand, it also asks: how is this arrangement of things justified and more importantly legitimated, what makes it seem right and proper? (p. 473) 
The assemblage is not therefore a means of engaging with the world via (a naïve form of) objectivism, where the constituents of assemblages are taken to be self-evident or simply described for their material properties (Brenner et al., 2011). Rather, the assemblage presents a socio-political entry point to unpacking the assumptions put forward by Euro-American modernity - concerning, for example, assumed relationships between ideal/material, nature/culture, humans/others - and of reconsidering ‘agency’ amongst its actors and constituents.

Drawing on Deleuze and Guattari, Fox and Alldred (2015, p. 402) enumerate implications of harnessing the assemblage in social empirical research, adopted here and paraphrased in relation to language studies:

- A shift in concern from defining the objects of research, to investigating capacities for action, interaction, affect, and flows;

- The character of the assemblage undermines the notion of a "determining social structure” shaping bodies, subjectivities and practices. Rather, attention is turned to spatiotemporally specific occurrences "within continual and continuous flows" in assemblages (see also Buchanan, 2008).

- The relationship and hierarchies between material/cultural, and micro/meso/macro i.e. different levels of analysis - are dissolved. Assemblages contain elements of all of these and invite attention to be paid to all of them as equally constitutive of spatiotemporally located events, situations, practices and interactions.

- Focus shifts from being to becoming - assemblages are always in a state of transformation.

- The production of knowledge also takes place within assemblages; the imposition of frames of order and structure onto data is itself a participant in the assemblage. 
This paper does not aim to prescribe the specific ways in which assemblages should be taken up as analytical tools in language studies. However, as a means to explore the potentiality of this mode of thinking, we tentatively outline some possibilities here. Assemblage thinking is applicable to any spatiotemporally located event where language is encountered: it is not restricted to certain instances of language, but rather to all and any of what might be considered 'language data' (noting that language is defined socially and culturally). This includes language data which adhere to ideologies of monolingualism and standardisation (for example, this paper). Paraphrasing Buchanan (2017), an assemblage analysis might begin with an instantiation of 'language' - for instance, a sign, sentence, word, multimodal text, gesture, spoken interaction, or other - and would then aim to understand the assemblage required to produce it (i.e. how it is composed): constitutive elements (bodies), relations between these, as well as the relations, arrangements and possibilities that these might produce. Buchanan (2017) emphasises that an important component of the analysis would address justification and legitimation - i.e. what makes the language assemblage seem normal, right, aberrant, (un)marked, or (in)visible? Approaching data in this manner resists framing social systems as determinative, or simply describing things 'as they appear'. The language assemblage constantly interplays with others; it stands to reason, therefore, that the production, recognition, and interpretation of language reoccurs within other assemblages, and is potentially subject to change across time and space.

Analytically, Barad’s (2007) agential cut has found popular articulation with assemblage thinking. The agential cut, differing from the Cartesian cut which separates subject and object (Barad, 2003), names the intra-action of material-discursive elements to demarcate, define and establish phenomena (see also Højgaard \& Søndergaard, 2011; Warfield, 2016). ${ }^{\mathrm{xv}}$ Working with agential cuts presents us with a set of questions. We might ask: how do we draw the boundaries around language, entangled, produced and interpreted 
within intra-actions? How is language demarcated and made recognisable? What materialdiscursive practices are involved in demarcating language, and allowing us to conceive of a language assemblage?

Assemblage thinking is itself an intervention or an actant in the assemblage, and the ways in which we engage in assemblage thinking (and recognise bodies, flows, forces, cuts) are bounded by our subjectivities and experiences (Anderson, Kearnes, McFarlane, \& Swanton, 2012; Greenhough, 2012). ${ }^{\text {xvi }}$ Thinking in assemblages moves language away from the post-Enlightenment scientific (empiricist, positivist, rationalist) method imposed by structural linguistics, opening up its theorisation to a different ontological possibility. The assemblage perspective fosters a materially-informed, dynamic view of language as social and cultural practice; it allows us to acknowledge the role of ideology in these practices, and the agency of actants to shape, reform, or reproduce the language assemblage. Matter participates in the assemblage, as bodies, sound, marks on a page; however, these elements shift, separate and re-converge, and are not interpreted in the same way across assemblages. ${ }^{\text {xvii }}$ In recognition of this, there is a need for further curiosity, and a willingness to engage critically with assemblage thinking in relation to language and languaging. A necessary component of this will be more deliberate engagement in interdisciplinary thought and research, including an openness to metaphysical questions about the nature of language, what it constitutes, and how and why it is demarcated as such.

\section{Critical language studies - approaching the ontological turn}

This paper began by tracing important poststructural accounts of language that move away from the multiplication of the monolingual, towards frameworks that seek to capture language plurality and languaging. There is a notable shift towards complex frameworks exemplified by (trans)languaging and metrolingualism - whose aim is to examine 
"boundaries and distinctions", and to ascertain how language is enacted and manipulated by its users within particular contexts (Otsuji \& Pennycook, 2010, p. 241). Moving away from stagnant and statist theories of language to models that radicalise how language is conceived and produced, we have brought these theoretical developments into further dialogue with assemblage thinking. Assemblages are alternative to unities; their components are not linked by intrinsic relations to perform functions "in the service of reproducing” relations between them (Nail, 2017, p. 22). Their analytical capacity arguably lies in their immanence, fluidity and horizontality, the external relations of their components, their (re)formations, and their capacities to produce. To paraphrase Grosz (1994), we could say that language as assemblage presents a way to understand languaging and languages "while refusing to subordinate [language] to a unit of a homogeneity” (p. 165) within social, cultural, and political depictions. This, arguably, fundamentally moves analysis away from a preoccupation with language ideology, and epistemologically conceived accounts of language, to a questioning of language ontology.

While ontology has long been the domain of philosophical inquiry, recent scholarship in anthropology and cultural studies has reengaged with ontology (see, for example, Blaser, 2009, 2016; Escobar, 2016; Law, 2015) to explore assumptions concerning the relationship between nature and society (or culture), and questions the origins and legitimacy of this separation. Scholars explicitly contesting Euro-American modernity have advocated that the presumed dualities of material/ideal-ideological, physical/spiritual and human/nonhuman be broken apart and reassembled horizontally on a non-hierarchical, post-dualistic plane (Deleuze \& Guattari, 1987; Ferrando, 2016; St. Pierre, 2013). Drawing on the work of Latour (1993), Heywood (2017) proposes that

[o]ur understanding of the world is inseparable from the world itself until we make that separation (a process Latour calls "purification”) and distil "natural” objects from 
"social” ones. This idea, of not assuming a division between the natural and the social, the ideal and the material, is a key plank of the ontological turn's platform. (para. 12)

When considering the ontology of language/languaging, this potentially disruptive thinking invites us to reconsider what language is and how it manifests - as a practice, product, or other. While these concerns are not necessarily new lines of inquiry in linguistic anthropology or critical language studies, there is an ongoing need and commitment to contest dominant ideologies and ontologies of language, in transdisciplinary conversation with fields such as philosophy, anthropology and education, including and perhaps in addition to assemblage thinking. Recent work in linguistic anthropology responds to the assertion that "what language is is not exhausted by the linguist's or anthropologist's descriptive categories” (Hauck \& Heurich, 2018, p. 1, emphasis in original); it is to this end that further research and thinking should be directed. Moving forward, there is scope for greater engagement with ontologies of language/languaging operating beyond or alongside what has been traced in this paper.

Culturally and politically determined conceptions of language can become reified to the extent that what language is, and what it does, are made invisible outside relatively discrete spheres of critical research. Possibilities for how language may be constituted ontologically are obscured by such conceptions. To theorise beyond this, what is required is reflexivity, and consideration of the ways in which our conceptions of language/languaging are mediated ideologically, socio-politically and materially. Heywood (2017) has similarly emphasised a commitment to having "no prior commitments" (p. 5) aside from openness to allowing empirical material to transform the ways in which we analyse and think about it. In particular relation to language/languaging, this presupposes having the theoretical and analytical capacity to make sense, methodologically, of the assemblages of language practice 
(which may open up our ideas of what our empirical materials actually are) rather than of the unidirectional application of language ideologies from above. 


\section{References}

Acuto, M., \& Curtis, S. (2014). Assemblage thinking and international relations. In M. Acuto \& S. Curtis (Eds.), Reassembling international theory (pp. 1-15). London, England: Palgrave Pivot.

Anderson, B., Kearnes, M., McFarlane, C., \& Swanton, D. (2012). On assemblages and geography. Dialogues in Human Geography, 2(2), 171-189.

Appleby, R., \& Pennycook, A. (2017). Swimming with sharks, ecological feminism and posthuman language politics. Critical Inquiry in Language Studies, 14(2), 239-261.

Auer, P. (2011). Code-switching/mixing. In R. Wodak, B. Johnstone, \& P. Kerswiill (Eds.), The SAGE handbook of sociolinguistics (pp. 460-478). London: SAGE Publications Ltd.

Barad, K. (2003). Posthumanist performativity: Toward an understanding of how matter comes to matter. Signs: Journal of Women in Culture and Society, 28(3), 801-831.

Barad, K. (2007). Meeting the universe halfway: Quantum physics and the entanglement of matter and meaning. Durham, NC: Duke University Press.

Becker, A. L. (1991). Language and languaging. Language \& Communication, 11, 33-35.

Bennett, J. (2010). Vibrant matter: A political ecology of things. Durham, NC: Duke University Press.

Blaser, M. (2009). Political ontology. Cultural Studies, 23(5-6), 873-896.

Blaser, M. (2016). Is another cosmopolitics possible? Cultural Anthropology, 31(4), 545-570. doi:10.14506/ca31.4.05

Bloome, D., \& Beauchemin, F. (2016). Languaging everyday life in classrooms. Literacy Research: Theory, Method, and Practice, 65(1), 152-165.

Brenner, N., Madden, D. J., \& Wachsmuth, D. (2011). Assemblage urbanism and the challenges of critical urban theory. City, 15(2), 225-240.

Buchanan, I. (2008). Power, theory and praxis. In I. Buchanan \& N. Thoburn (Eds.), Deleuze and politics (pp. 13-34). Edinburgh, Scotland: Edinburgh University Press.

Buchanan, I. (2017). Assemblage theory, or, the future of an illusion. Deleuze Studies, 11(3), 457-474.

Canagarajah, A. S. (2006). After disinvention: Possibilities for communication, community and competence. In S. Makoni \& A. Pennycook (Eds.), Disinventing and reconstituting languages (pp. 233-239). UK: Multilingual Matters. 
Canagarajah, A. S. (2017). Translingual practices and neoliberal policies. Cham, Switzerland: Springer.

Canagarajah, A. S., \& Ashraf, H. (2013). Multilingualism and education in South Asia: Resolving policy/practice dilemmas. Annual Review of Applied Linguistics, 33, 258285.

Del Valle, J. (2000). Monoglossic policies for a heteroglossic culture: Misinterpreted multilingualism in modern Galicia. Language \& Communication, 20, 105-132.

DeLanda, M. (2006). A new philosophy of society: Assemblage theory and social complexity. London, UK: Continuum.

Deleuze, G. (1990). The logic of sense (M. Lester \& C. Stivale, Trans. C. V. Boundas Ed.). New York: Columbia University Press.

Deleuze, G., \& Guattari, F. (1987). A thousand plateaus: Capitalism and schizophrenia (B. Massumi, Trans.). London, UK: Continuum.

Demuro, E., \& Gurney, L. (2018). Mapping language, culture, ideology: Rethinking language in foreign language instruction. Language and Intercultural Communication, 18(3), 287-299. doi:10.1080/14708477.2018.1444621

Dewsbury, J. D. (2011). The Deleuze-Guattarian assemblage: Plastic habits. Area, 43(2), 148-153.

Escobar, A. (2016). Thinking-feeling with the Earth: Territorial struggles and the ontological dimension of the epistemologies of the south. Revista de Antropología Iberoamericana, 11(1), 11-32.

Ferrando, F. (2016). Humans have always been posthuman: A spiritual geneaology of posthumanism. In D. Banerji \& M. R. Paranjape (Eds.), Critical posthumanism and planetary futures (pp. 243-256). New Delhi, India: Springer.

Fox, N. J., \& Alldred, P. (2015). New materialist social inquiry: Designs, methods and the research-assemblage. International Journal of Social Research Methodology, 18(4), 399-414.

García, O., \& Li, W. (2014). Translanguaging: Language, bilingualism and education. London, England: Palgrave MacMillan.

Gillies, D. (2017). Human capital theory in education. In M. A. Peters (Ed.), Encyclopedia of educational philosophy and theory (pp. 1053-1057). Singapore: Springer Singapore. 
Goldrick, M., Putnam, M., \& Schwarz, L. (2016). Coactivation in bilingual grammars: A computational account of code mixing. Bilingualism: Language and Cognition, 19(5), 857-876.

Gramling, D. (2016). The invention of monolingualism. New York, NY: Bloomsbury Academic.

Greenhough, B. (2012). On the agencement of the academic geographer. Dialogues in Human Geography, 2(2), 202-206.

Grosz, E. (1994). Volatile bodies: Toward a corporeal feminism. Sydney, Australia: Allen and Unwin.

Harris, R. (1980). The language-makers. London, England: Duckworth.

Harris, R. (1999). Integrational linguistics and the structuralist legacy. Language \& Communication, 19(1), 45-68.

Hauck, J. D., \& Heurich, G. O. (2018). Language in the Amerindian imagination: An inquiry into linguistic natures. Language \& Communication, 63, 1-8.

Heywood, P. (2017). The ontological turn. Cambridge encyclopedia of anthropology. Retrieved from http://www.anthroencyclopedia.com/entry/ontological-turn\#h2ref-1

Højgaard, L., \& Søndergaard, D. M. (2011). Theorizing the complexities of discursive and material subjectivity: Agential realism and poststructural analyses. Theory \& Psychology, 21(3), 338-354.

Kubota, R., \& Miller, E. R. (2017). Re-examining and re-envisioning criticality in language studies: Theories and praxis. Critical Inquiry in Language Studies, 14(2-3), 129-157.

Larsen-Freeman, D. (2015). Saying what we mean: Making a case for "language acquisition” to become "language development”. Language Teaching, 48(04), 491-505.

Latour, B. (1993). We have never been modern (C. Porter, Trans.). Cambridge, MA: Harvard University Press.

Law, J. (2015). What's wrong with a one-world world? Distinktion: Journal of Social Theory, 16(1), 126-139. doi:10.1080/1600910X.2015.1020066

Lewis, G., Jones, B., \& Baker, C. (2012). Translanguaging: Developing its conceptualisation and contextualisation. Educational Research and Evaluation, 18(7), 655-670.

Li, W. (2018). Translanguaging as a practical theory of language. Applied Linguistics, 39(1), 9-30.

Litaker, J. (2014). Assemblage. In P. Ardoin, S. E. Gontarski, \& L. Mattison (Eds.), Understanding modernism (pp. 251-252). New York, NY: Bloomsbury Academic. 
Love, N. (2004). Cognition and the language myth. Language Sciences, 26(6), 525-544.

Love, N. (2009). Science, language and linguistic culture. Language \& Communication, 29(1), 26-46.

Love, N. (Ed.) (2006). Language and history: Integrationist perspectives. London, UK: Routledge.

MacLure, M. (2013). Researching without representation? Language and materiality in postqualitative methodology. International Journal of Qualitative Studies in Education, 26(6), 658-667.

Maher, J. C. (2005). Metroethnicity, language, and the principle of cool. International Journal of the Sociology of Language(175-176), 83-102.

Makoni, S., \& Pennycook, A. (2006). Disinventing and reconstituting languages. In S. Makoni \& A. Pennycook (Eds.), Disinventing and reconstituting languages (pp. 141). London, UK: Multilingual Matters.

Mar-Molinero, C. (2004). Spanish as a world language: Language and identity in a global era. Spanish in Context, 1(1), 3-20.

Marshall, S., \& Moore, D. (2018). Plurilingualism amid the panoply of lingualisms: Addressing critiques and misconceptions in education. International Journal of Multilingualism, 15(1), 19-34.

May, S. (2014). Contesting public monolingualism and diglossia: Rethinking political theory and language policy for a multilingual world. Language Policy, 13(4), 371-393.

McNamara, T. (2012). Poststructuralism and challenges for applied linguistics. Applied Linguistics, 33, 473-482.

Müller, M. (2015). Assemblages and actor-networks: Rethinking socio-material power, politics and space. Geography Compass, 9(1), 27-41.

Nail, T. (2017). What is an assemblage? SubStance, 46(1), 21-37.

Orman, J. (2013). New lingualisms, same old codes. Language Sciences, 37, 90-98.

Otsuji, E., \& Pennycook, A. (2010). Metrolingualism: Fixity, fluidity and language in flux. International Journal of Multilingualism, 7(3), 240-254.

Park, J. S. Y. (2016). Language as pure potential. Journal of Multilingual and Multicultural Development, 37(5), 453-466.

Pennycook, A. (2017). Translanguaging and semiotic assemblages. International Journal of Multilingualism, 14(3), 269-282. 
Pennycook, A. (2018a). Posthumanist applied linguistics. Applied Linguistics, 39(4), 445461.

Pennycook, A. (2018b). Posthumanist applied linguistics. Abingdon, England: Routledge.

Pennycook, A., \& Otsuji, E. (2014). Metrolingual multitasking and spatial repertoires: 'Pizza mo two minutes coming'. Journal of Sociolinguistics, 18(2), 161-184.

Pennycook, A., \& Otsuji, E. (2017). Fish, phone cards and semiotic assemblages in two Bangladeshi shops in Sydney and Tokyo. Social Semiotics, 27(4), 434-450.

Pennycook, A., \& Otsuji, E. (2019). Mundane metrolingualism. International Journal of Multilingualism, 16(2), 175-186.

Phillips, J. (2006). Agencement/Assemblage. Theory, Culture \& Society, 23(2-3), 108-109.

St. Pierre, E. A. (2013). The posts continue: Becoming. International Journal of Qualitative Studies in Education, 26(6), 646-657.

Taylor, C. (2013). Objects, bodies and space: Gender and embodied practices of mattering in the classroom. Gender and Education, 25(6), 688-709.

Thibault, P. J. (2011). First-order languaging dynamics and second-order language: The distributed language view. Ecological Psychology, 23(2), 210-245.

Thibault, P. J. (2017). The reflexivity of human languaging and Nigel Love's two orders of language. Language Sciences, 61, 74-85.

Toolan, M. (2003). An integrational linguistic view of coming into language. In J. Leather \& J. van Dam (Eds.), Ecology of language acquisition (pp. 123-139). Dordrecht, the Netherlands: Kluwer Academic Publishers.

Warfield, K. (2016). Making the cut: An agential realist examination of selfies and touch. Social Media + Society, 2(2), 1-10.

Wood, D. M. (2013). What is global surveillance? Towards a relational political economy of the global surveillant assemblage. Geoforum, 49, 317-326.

Woolard, K. A., \& Schieffelin, B. B. (1994). Language ideology. Annual Review of Anthropology, 23, 55-82.

\footnotetext{
${ }^{i}$ Notwithstanding this shift, much theorisation on multilingualism perpetuates hegemonic categories used to describe linguistic behaviour. These categories, themselves products of socio-political developments, have been critiqued as historically determined abstractions of cultural tradition
} 
(Orman, 2013; Seargeant \& Tagg, 2011) which not only reproduce reductionist language ideologies but are potential impediments to the development of more comprehensive understandings of language.

${ }^{\text {ii }}$ Gramling (2016) further explains the linguistic context of pre-modern Europe, stating that "most non-elite medium-distance travelers had neither a conceptual map nor a pertinent reason for identifying a neighboring region's speech as structurally foreign from their own. Difficulties in understanding would tend to strike the traveler as features of acoustic or social friction in the flow of communication, rather than as results of any discrete language barrier. A modern structuralist's potential rebuttal—-that this happy traveler just doesn't understand the fundamentals of linguistics yet-misses the emic, practical point about situated knowledge in pre-modernity, while also indicating a more general disinterest in, or discomfort with, vernacular modes of language use beyond the reach of systemic or philological models” (p. 8).

iii For example, the ability to use prestigious language codes, such as North American/British English or Iberian (Castilian) Spanish, is discussed as a form of widely-recognised capital, contributing to a healthy trade on linguistic commodities.

${ }^{\text {iv }}$ As $\mathrm{Li}$ (2018) defines, the addition of the trans prefix expands the term by referring to "the fluid practices that go beyond, i.e., transcend, socially constructed language systems and structures to engage diverse multiple meaning-making systems and subjectivities; the transformative capacity of the Translanguaging process not only for language systems but also for individuals' cognition and social structures; and the transdisciplinary consequences of re-conceptualizing language, language learning, and language use, and working across the divides between linguistics, psychology, sociology, and education” (p. 27).

${ }^{v}$ Otsuji and Pennycook (2010) explain that metrolingualism paves the way for the "reconstitution of language and an alternative way of being in and through ludic and other possibilities of the everyday” (p. 246).

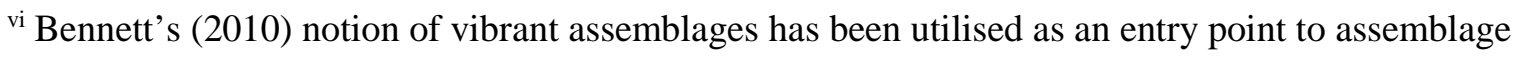
thinking in the language context (see Appleby \& Pennycook, 2017; Pennycook, 2017; Pennycook \& Otsuji, 2017). Whilst Bennett's work is not seminal in materialist ontologies or theorisation of the assemblage, it provides a particular perspective on the assemblage, agency, and matter (one which we do not aim to critique per se in this paper).

vii Deleuze and Guattari (1987) further explain that "[a]n assemblage, in its multiplicity, necessarily acts on semiotic flows, material flows, and social flows simultaneously ... there is no longer a tripartite division between a field of reality (the world) and a field of representation (the book) and a field of subjectivity (the author). Rather, an assemblage establishes connections between certain multiplicities drawn from each of these orders ...” (pp. 22-23).

viii DeLanda (2006) states that a unity is a "seamless totality" (p. 9). 
ix The term assemblage, as a translation of agencement, has potential to generate confusion; while it captures that "an assemblage/agencement consists of multiple, heterogeneous parts linked together to form a whole” (Müller, 2015, p. 28), it is perhaps not so clear from the translation that assemblages themselves create agency (Bennett, 2010; Müller, 2015).

${ }^{x}$ DeLanda (2006) further summarises the composition of assemblages, stating: "unlike wholes in which parts are linked by relations of interiority (that is, relations which constitute the very identity of the parts) assemblages are made up of parts which are self-subsistent and articulated by relations of exteriority, so that a part may be detached and made a component of another assemblage. Assemblages are characterized along two dimensions: along the first dimension are specified the variable roles which component parts may play, from a purely material role to a purely expressive one, as well as mixtures of the two. A second dimension characterizes processes in which these components are involved: processes which stabilize or destabilize the identity of the assemblage (territorialization and reterritorialization). [...] [A] third dimension will be added: an extra axis defining processes in which specialized expressive media intervene, processes which consolidate and rigidify the identity of the assemblage or, on the contrary, allow the assemblage a certain latitude for more flexible operation while benefiting from genetic or linguistic resources (processes of coding and decoding)” (pp. 18-19).

xi Referencing Kafka's The Trial and The Castle, Müller (2015) gives the following metaphor for the assemblage: "everything seems linked to everything else: there are new, unexpected realities at each turn, entities congeal just to fall apart in the next instance and desire to reach an elusive goal (the castle and the end of the trial) recomposes them anew every time” (p. 29).

xii As Deleuze (1990) continues, “[o]ne speaks always of bodies and their mixtures, but sounds have ceased being qualities attached to these bodies in order that they may enter into a new relation with them, that of denotation, and that they may express this power of speaking and of being spoken” (pp. 181-182). This constructed denotation enters into the assemblage anew - as the particle transfers from body to sign to body (Deleuze \& Guattari, 1987).

xiii This, of course, is an acknowledgment of the unavoidable impasse of writing about language from within language itself; of speaking within and across the assemblage.

${ }^{x i v}$ So called ideational elements of the language assemblage are deposed from their position of standing above and looking down at physical milieu and time-bound interactions (MacLure, 2013). Conceptually, as Dewsbury (2011) posits, “[t]he body-brain-material assemblage operates an exciting proposition [...] through readings of neuroscience and alternative philosophies of nature the relationship between thought and matter is placed in conceptual tension such that thought is matter and matter is thought” (p. 151).

${ }^{x v}$ Here, phenomena result from the intra-action of an 'object' and 'measuring agencies' which identify it (Barad, 2007): “... it is through these agential cuts and through specific intra-active 
practices that boundaries, categories, and "properties" of phenomena are established, and it is also through these cuts that specific concepts - specific material-discursive articulations of the world—become meaningful” (Højgaard \& Søndergaard, 2011, p. 346). Barad’s (2007) notion has been taken up in different ways across domains of research (see for instance Taylor, 2013; Warfield, 2016), grounded in an acceptance of entanglement and relationality, rather than separability. As neatly summarised by Warfield (2016), Barad's agential realist approach “is interested not in interactions between predefined entities, but the intra-actions that occur within the entanglements of phenomenon [sic] that enact boundaries, which then demarcate entities as separate from one another" (p. 2).

${ }^{\text {xvi }}$ Greenhough (2012) notes the following in the content of geography, which we argue is applicable to assemblage thinking in language studies: "[w]e need to attend to the agencement of the academic geographer, who, while contingent, partial and open to new possible relations, nonetheless remains subject to the tendency of falling back into 'relatively stable forms and relations' (such as the mantra of race, class, gender, and sexuality; Schueller, 2005). This is a problematic already acknowledged in attempts to develop novel methodologies for engaging with more-than-socially constructed worlds ... We face the problem of how to tell non-linear geographies from within the resilient assembled tool-kits of academic research, writing and publishing.” (p. 204)

${ }^{\text {xvii }}$ Linguistic behaviour encompasses "the integration and orchestration of neural, bodily, situational, social, and cultural processes spanning a diversity of time scales ... animated by the dynamics of living, feeling, moving bodies, not abstract forms” (Thibault, 2017, p. 76). Further, the identification of linguistic behaviour is itself premised on such processes spanning a diversity of time scales. 